\title{
Techniques to measure rigidity of ankle-foot orthosis: A review
}

\author{
Toshiki Kobayashi, PhD; ${ }^{1 *}$ Aaron K. L. Leung, PhD; ${ }^{2}$ Stephen W. Hutchins, $\mathbf{P h D}^{\mathbf{3}}$ \\ ${ }^{1}$ Orthocare Innovations, Mountlake Terrace, WA; ${ }^{2}$ Department of Health Technology and Informatics, The Hong Kong \\ Polytechnic University, Hong Kong, People's Republic of China; ${ }^{3}$ Centre for Health, Sport and Rehabilitation Sciences \\ Research, University of Salford, Salford, UK
}

\begin{abstract}
We performed this review to provide a clearer understanding of how to effectively measure ankle-foot orthosis (AFO) rigidity. This information is important to ensure appropriate orthotic intervention in the treatment of patients with pathological gait. The two main approaches to the investigation of AFO rigidity are (1) bench-testing analyses, in which an AFO is fixed or attached to a measurement device, and (2) functional analyses, in which measurements are taken while a subject is walking with an AFO in situ. This review summarizes and classifies the current state of knowledge of AFO rigidity testing methods. We analyzed the strengths and weaknesses of the methods in order to recommend the most reliable techniques to measure AFO rigidity. The information obtained from this review article would, therefore, benefit both clinicians and engineers involved in the application and design of AFOs.
\end{abstract}

Key words: AFO, ankle-foot orthosis, cerebral palsy, flexibility, hemiplegia, mechanical test, rigidity, spinal cord injury, stiffness, stroke, testing and measurement.

\section{INTRODUCTION}

Ankle-foot orthoses (AFOs) are used to improve pathological gait [1]. Therefore, the biomechanical function of a prescribed AFO must closely match the needs of the patient [1]. Indeed, evidence in the literature demonstrates that an optimal match exists between patient's gait-related problems and the rigidity of an AFO [2-4].

The rigidity of an AFO has been measured with the use of various parameters, including stiffness, resistive moments, and strains [4-6]. The inherent rigidity of an AFO plays an important role in determining its biome- chanical function and needs to be optimal to positively influence the gait of patients with gait pathologies [7-8]. The rigidity of an AFO may be determined by a number of factors, such as the mechanical properties of the material; the trimlines; the material thickness; and the shape of the superstructure, especially at malleoli level [9-12]. An enhanced understanding of the interaction between various AFO designs and rigidity could therefore improve the clinical decision-making process. However, before the relationship between AFO designs and rigidity is determined, the processes used to measure the rigidity characteristics of different AFO designs need to be critiqued.

AFO rigidity measurements have previously involved two main methods: (1) bench testing and (2) functional analyses [5]. With a bench-testing method, rigidity parameters are measured with an AFO fixed or attached to a measurement apparatus, while with a functional method, these parameters are measured while a subject is walking with the aid of an AFO [5]. Various types of apparatuses, sensors, or experimental AFOs have been designed to analyze AFO performance. Although variations in AFO rigidity analysis methods may be due to different requirements

Abbreviations: AFO = ankle-foot orthosis, DACS $=$ dorsiflexion assist controlled by spring, G-study = generalizability study, MTP = metatarsophalangeal.

${ }^{*}$ Address all correspondence to Toshiki Kobayashi, PhD; Orthocare Innovations, 6405 218th Street SW, Suite 301, Mountlake Terrace, WA 98043-2180; 800-672-1710; fax: 206219-1144. Email: tkobayashi@orthocareinnovations.com DOI:10.1682/JRRD.2010.10.0193 
in answering the research hypotheses of various studies, establishing some criteria to provide quality control in industry and facilitate appropriate AFO prescriptions in the clinical setting would be advantageous.

The specific aims of this article were therefore to review studies in the literature regarding methods used to investigate AFO rigidity and to analyze and contrast the strengths and weaknesses of current techniques as well as published reliability and repeatability data. The information obtained from this review article will help both clinicians and engineers by highlighting the importance of undertaking rigidity analysis of AFOs. The information obtained may be applied in the clinical setting to better clarify the relationship between AFO rigidity and patient outcomes and in the industrial setting to evaluate new AFO designs or develop novel AFO testing methods.

\section{METHODS}

A literature search was conducted in Google Scholar, Scopus, CINAHL, MEDLINE, Cochrane Database, and RECAL, and cited references from appropriate articles were thoroughly reviewed. The key words used were "ankle-foot orthosis (AFO)," "bending," "stiffness," "rigidity," and "testing." Inclusion criteria for this review article included articles in which-

1. Analysis of AFO rigidity was conducted either under bench testing or functional conditions.

2. Analysis was conducted mechanically and not computationally (e.g., finite element analysis) alone.

3 . The means of analysis, such as type of sensors used and its methods, were clearly explained.

4. The study was published in a peer-reviewed journal in English.

\section{RESULTS AND COMMENTS}

No comparative reviews regarding measurement techniques for AFO rigidity were found in the literature. The literature search identified 25 suitable articles for bench testing analyses and 10 articles for functional analyses (Table) [2,4,6-38]. Therefore, a total of 35 articles were included in this review article. From these, current measuring techniques and their accuracy and reliability were compared and analyzed and recommendations were made for future studies.

\section{Methods of Testing Ankle-Foot Orthosis Rigidity}

The majority of the studies found in the literature involved bench testing analysis and were broadly assigned into categories; all used hardware to apply and/or measure the force applied or measure the subsequent deflection, strain, or bending moments applied to or by the AFO by investigating the moment-angle or moment-deflection relationships. Methods used to achieve the force application and/or measure the subsequent deflection or strain during bench testing included a tensionmeter [4,9-10,13$16]$, a dial gauge [12,17-18], a strain gauge or a load cell [2,21-24], a forceplate [11], a muscle training machine [25-26], and a mechanical testing machine [5,27-30].

Functional analysis involved the use of gait analysis and strategies that provide AFO performance indicators using strain gauges [6,31-34] or an experimental AFO [7-8,35-37].

\section{Bench Testing Analysis}

\section{Studies Using Tensionmeters}

A tensionmeter can measure the applied load and quantify AFO rigidity by directly applying of force to a specific area of the AFO. An analog or digital tensionmeter has been used in combination with a digital goniometer $[10,13]$ or a protractor $[4,9,16]$ to examine the force-angle or moment-angle relationship. Use of a tensionmeter would be the most convenient and inexpensive way to measure rigidity; however, the position and direction of applied force induced by the tensionmeter would critically affect the amount of deformation of the AFO. The evidence in the literature revealed that a tensionmeter was either attached to the superior rim of the posterior wall $[9-10,15]$ or the metatarsal region [13] of the AFO. It was also attached to a bar connected to a rotational axis of a surrogate limb, which was fitted within the AFO $[4,16]$. Accurately defining the position and direction of force is therefore critically important for measurement accuracy and repeatability. The device developed by Sumiya et al. is a good example that could control both parameters [16]. Clinical use of an apparatus built with a tensionmeter seems realistic once its reliability is established.

\section{Studies Using Dial Gauges}

A dial gauge can measure small linear displacement of an AFO as a result of deflection. An analog dial gauge has been used with weights for controlled application of deflection. Precedence studies have computed AFO resistance 
Table.

Summary of reviewed articles.

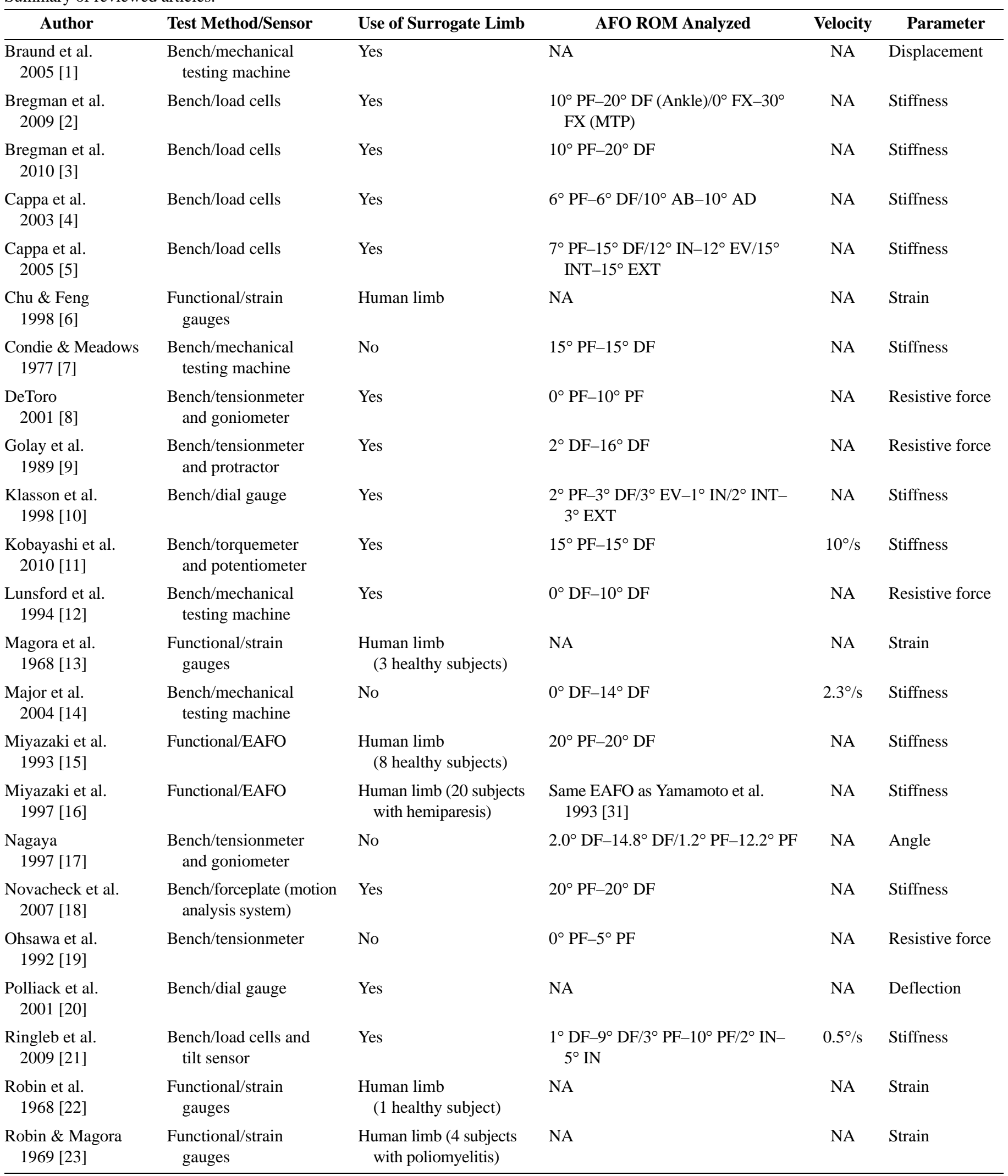


JRRD, Volume 48, Number 5, 2011

Table. (cont)

Summary of reviewed articles.

\begin{tabular}{|c|c|c|c|c|c|}
\hline Author & Test Method/Sensor & Use of Surrogate Limb & AFO ROM Analyzed & Velocity & Parameter \\
\hline $\begin{array}{r}\text { Robin et al. } \\
1971 \text { [24] }\end{array}$ & Functional/strain gauges & $\begin{array}{l}\text { Human limb (4 subjects } \\
\text { with poliomyelitis) }\end{array}$ & NA & NA & Strain \\
\hline $\begin{array}{l}\text { Ross et al. } \\
1999 \text { [25] }\end{array}$ & Bench/dial gauge & No & NA & NA & Displacement \\
\hline $\begin{array}{l}\text { Rubin \& Dixon } \\
1973 \text { [26] }\end{array}$ & Bench/tensionmeter & No & NA & NA & Resistive force \\
\hline $\begin{array}{l}\text { Singerman et al. } \\
1999 \text { [27] }\end{array}$ & Bench/strain gauges & Yes & $10^{\circ} \mathrm{PF}-10^{\circ} \mathrm{DF}$ & NA & Stiffness \\
\hline $\begin{array}{l}\text { Sumiya et al. } \\
1996 \text { [28] }\end{array}$ & $\begin{array}{l}\text { Bench/tensionmeter } \\
\text { and protractor }\end{array}$ & Yes & $0^{\circ} \mathrm{PF}-15^{\circ} \mathrm{PF}$ & $2 \% \mathrm{~s}$ & $\begin{array}{l}\text { Resistive } \\
\text { moment }\end{array}$ \\
\hline $\begin{array}{l}\text { Sumiya et al. } \\
1996 \text { [29] }\end{array}$ & $\begin{array}{l}\text { Bench/tensionmeter } \\
\text { and protractor }\end{array}$ & Yes & $15^{\circ} \mathrm{DF}-15^{\circ} \mathrm{PF}$ & $2 \%$ & $\begin{array}{l}\text { Resistive } \\
\text { moment }\end{array}$ \\
\hline $\begin{array}{l}\text { Yamamoto et al. } \\
1993 \text { [30] }\end{array}$ & Functional/EAFO & $\begin{array}{l}\text { Human limb (2 subjects } \\
\text { with hemiparesis) }\end{array}$ & $\begin{array}{l}\text { Same EAFO as Miyazaki et al. } \\
1993 \text { [15] }\end{array}$ & NA & Stiffness \\
\hline $\begin{array}{l}\text { Yamamoto et al. } \\
1993 \text { [31] }\end{array}$ & Functional/EAFO & $\begin{array}{l}\text { Human limb (15 subjects } \\
\text { with hemiparesis) }\end{array}$ & $10^{\circ} \mathrm{PF}-20^{\circ} \mathrm{DF}$ & NA & Stiffness \\
\hline $\begin{array}{l}\text { Yamamoto et al. } \\
1993 \text { [32] }\end{array}$ & $\begin{array}{l}\text { Bench/muscle training } \\
\text { machine }\end{array}$ & Human limb & $20^{\circ} \mathrm{PF}-15^{\circ} \mathrm{DF} 15^{\circ} \mathrm{IN}-10^{\circ} \mathrm{EV}$ & $\begin{array}{l}5 \% 10 \% \\
\text { and } 50 \% \mathrm{~s}\end{array}$ & Stiffness \\
\hline $\begin{array}{l}\text { Yamamoto et al. } \\
1997 \text { [33] }\end{array}$ & Functional/EAFO & $\begin{array}{l}\text { Human limb (33 subjects } \\
\text { with hemiparesis) }\end{array}$ & $\begin{array}{l}\text { Same EAFO as Yamamoto et al. } \\
1993 \text { [31] }\end{array}$ & NA & Stiffness \\
\hline $\begin{array}{l}\text { Yamamoto et al. } \\
1999 \text { [34] }\end{array}$ & $\begin{array}{l}\text { Bench/strain gauges and } \\
\text { potentiometer }\end{array}$ & No & $10^{\circ} \mathrm{PF}-30^{\circ} \mathrm{DF}$ & NA & Stiffness \\
\hline $\begin{array}{l}\text { Yamamoto et al. } \\
2005 \text { [35] }\end{array}$ & $\begin{array}{l}\text { Bench/muscle testing } \\
\text { machine }\end{array}$ & No & $10^{\circ} \mathrm{PF}-20^{\circ} \mathrm{DF}$ & $\begin{array}{l}1 \%, 10 \% \\
\text { and } 20 \% \mathrm{~s}\end{array}$ & Stiffness \\
\hline
\end{tabular}

1. Braund M, Kroontje D, Brooks J, Self B, Aaron G, Bearden K. Analysis of stiffness reduction in varying curvature ankle foot orthoses. Biomed Sci Instrum. 2005;41:19-24. [PMID: 15850076]

2. Bregman DJ, Rozumalski A, Koops D, De Groot V, Schwartz M, Harlaar J. A new method for evaluating ankle foot orthosis characteristics: BRUCE. Gait Posture. 2009;30(2):144-49. [PMID: 19520576] DOI:10.1016/j.gaitpost.2009.05.012

3. Bregman DJ, De Groot V, Van Diggele P, Meulman H, Houdijk H, Harlaar J. Polypropylene ankle foot orthoses to overcome drop-foot gait in central neurological patients: A mechanical and functional evaluation. Prosthet Orthot Int. 2010;34(3):293-304. [PMID: 20738233] DOI:10.3109/03093646.2010.495969

4. Cappa P, Patanè F, Pierro MM. A novel device to evaluate the stiffness of ankle-foot orthosis devices. J Biomech Eng. 2003;125(6):913-17. [PMID: 14986419] DOI:10.1115/1.1634993

5. Cappa P, Patanè F, Di Rosa G. A continuous loading apparatus for measuring three-dimensional stiffness of ankle-foot orthoses. J Biomech Eng. 2005;127(6): 1025-29. [PMID: 1643244] DOI:10.1115/1.2049313

6. Chu TM, Feng R. Determination of stress distribution in various ankle-foot orthoses: Experimental stress analysis. J Prosthet Orthot. 1998;10(1):11-16. DOI:10.1097/00008526-199801010-00004

7. Condie DN, Meadows CB. Some biomechanical considerations in the design of ankle-foot orthoses. Orthot Prosthet. 1977;31(3):45-52.

8. DeToro WW. Plantarflexion resistance of selected ankle-foot orthoses: A pilot study of commonly prescribed prefabricated and custom-molded alternatives. J Prosthet Orthot. 2001;13(2):39-44. DOI:10.1097/00008526-200106000-00012

9. Golay W, Lunsford T, Lunsford BR, Greenfield J. The effect of malleolar prominence on polypropylene AFO rigidity and buckling. J Prosthet Orthot. 1989; 1(4):231-42. DOI:10.1097/00008526-198907000-00007

10. Klasson B, Convery P, Raschke S. Test apparatus for the measurement of the flexibility of ankle-foot orthoses in planes other than the loaded plane. Prosthet Orthot Int. 1998;22(1):45-53. [PMID: 9604275]

11. Kobayashi T, Leung AK, Akazawa Y, Naito H, Tanaka M, Hutchins SW. Design of an automated device to measure sagittal plane stiffness of an articulated ankle-foot orthosis. Prosthet Orthot Int. 2010;34(4):439-48. [PMID: 20681928] DOI:10.3109/03093646.2010.495370

12. Lunsford TR, Ramm T, Miller JA. Viscoelastic properties of plastic AFOs. J Prosthet Orthot. 1994;6(1):3-9. DOI:10.1097/00008526-199400610-00002

13. Magora A, Robin GC, Adler E, Libai A, Eitan A. Dynamic strain analysis of below-knee orthopedic braces. A preliminary report. Am J Phys Med. 1968;47(1): 31-40. [PMID: 5644317] 
Table. (cont)

Summary of reviewed articles.

14. Major RE, Hewart PJ, MacDonald AM. A new structural concept in moulded fixed ankle foot orthoses and comparison of the bending stiffness of four constructions. Prosthet Orthot Int. 2004;28(1):44-48. [PMID: 15171577]

15. Miyazaki S, Yamamoto S, Ebina M, Iwasaki M. A system for the continuous measurement of ankle joint moment in hemiplegic patients wearing ankle-foot orthoses. Front Med Biol Eng. 1993;5(3):215-32. [PMID: 8280669]

16. Miyazaki S, Yamamoto S, Kubota T. Effect of ankle-foot orthosis on active ankle moment in patients with hemiparesis. Med Biol Eng Comput. 1997;35(4):381-85. [PMID: 9327616] DOI:10.1007/BF02534094

17. Nagaya M. Shoehorn-type ankle-foot orthoses: Prediction of flexibility. Arch Phys Med Rehabil. 1997;78(1):82-84. [PMID: 9014963$]$ DOI:10.1016/S0003-9993(97)90015-0

18. Novacheck TF, Beattie CB, Rozumalski A, Gent G, Kroll G. Quantifying the spring-like properties of ankle-foot orthoses (AFOs). J Prosthet Orthot. 2007; 19(4):98-103. DOI:10.1097/JPO.0b013e31812e555e

19. Ohsawa S, Ikeda S, Tanaka S, Takahashi T, Takeuchi T, Utsunomiya M, Ueno R, Ohkura M, Ito Y, Katagi Y, Ueta M, Hirano T. A new model of plastic ankle foot orthosis (FAFO (II)) against spastic foot and genu recurvatum. Prosthet Orthot Int. 1992;16(2):104-8. [PMID: 1408667]

20. Polliack AA, Swanson C, Landsberger SE, McNeal DR. Development of a testing apparatus for structural stiffness evaluation of ankle-foot orthoses. J Prosthet Orthot. 2001;13(3):74-82. DOI:10.1097/00008526-200109000-00012

21. Ringleb SI, Armstrong T, Berglund LJ, Kitaoka HB, Kaufman KR. Stiffness of the Arizona ankle-foot orthosis before and after modification for gait analysis. J Prosthet Orthot. 2009;21(4):204-7. DOI:10.1097/JPO.0b013e3181bfb28e

22. Robin GC, Magora A, Adler E, Saltiel J. Dynamic stress analysis of below-knee drop foot braces. Med Biol Eng. 1968;6(5):533-46. [PMID: 5713523] DOI:10.1007/BF02474292

23. Robin GC, Magora A. Dynamic stress analysis of below-knee drop foot braces; Studies on patients with paralysis of the lower limb. Med Biol Eng. 1969;7(2): 221-26. [PMID: 5802207] DOI:10.1007/BF02474178

24. Robin GC, Magora A, Saltiel J, Adler E. Dynamic analysis of plastic below-knee drop foot braces. Med Biol Eng. 1971;9(6):631-36. [PMID: 5158815] DOI:10.1007/BF02474643

25. Ross RS, Greig RJ, Convery P. Comparison of bending stiffness of six different colours of copolymer polypropylene. Prosthet Orthot Int. 1999;23(1):63-71. [PMID: 10355646]

26. Rubin G, Dixon M. Modern ankle-foot orthoses (AFO’s). Bull Prosthet Res. 1973;10(19):20-41. [PMID: 4358417]

27. Singerman R, Hoy DJ, Mansour JM. Design changes in ankle-foot orthoses intended to alter stiffness also alter orthosis kinematics. J Prosthet Orthot. 1999; 11(3):48-55. DOI:10.1097/00008526-199901130-00002

28. Sumiya T, Suzuki Y, Kasahara T. Stiffness control in posterior-type plastic ankle-foot orthoses: Effect of ankle trimline. Part 2: Orthosis characteristics and orthosis/patient matching. Prosthet Orthot Int. 1996;20(2):132-37. [PMID: 8876008]

29. Sumiya T, Suzuki Y, Kasahara T. Stiffness control in posterior-type plastic ankle-foot orthoses: Effect of ankle trimline. Part 1: A device for measuring ankle moment. Prosthet Orthot Int. 1996;20(2):129-31. [PMID: 8876007]

30. Yamamoto S, Ebina M, Kubo S, Kawai H, Hayashi, T, Iwasaki M, Kubota T, Miyazaki S. Quantification of the effect of dorsi-/plantarflexibility of ankle-foot orthoses on hemiplegic gait: A preliminary report. J Prosthet Orthot. 1993;5(3):88-94.

31. Yamamoto S, Miyazaki S, Kubota T. Quantification of the effect of the mechanical property of ankle-foot orthoses on hemiplegic gait. Gait Posture. 1993;1(1):27-34. DOI:10.1016/0966-6362(93)90040-8

32. Yamamoto S, Ebina M, Iwasaki M, Kubo S, Kawai H, Hayashi T. Comparative study of mechanical characteristics of plastic AFOs. J Prosthet Orthot. 1993; 5(2):59-64.

33. Yamamoto S, Ebina M, Miyazaki S, Kawai H, Kubota T. Development of a new ankle-foot orthosis with dorsiflexion assist, part 1: Desirable characteristics of ankle-foot orthoses for hemiplegic patients. J Prosthet Orthot. 1997;9(4):174-79. DOI:10.1097/00008526-199700940-00009

34. Yamamoto S, Ebina M, Kubo S, Hayashi T, Akita Y, Hayakawa Y. Development of a new ankle-foot orthosis with dorsiflexion assist, part 2: Structure and evaluation. J Prosthet Orthot. 1999;11(2):24-28.

35. Yamamoto S, Hagiwara A, Mizobe T, Yokoyama O, Yasui T. Development of an ankle-foot orthosis with an oil damper. Prosthet Orthot Int. 2005;29(3):209-19. [PMID: 16466151] DOI:10.1080/03093640500199455

$\mathrm{AB}=$ abduction, $\mathrm{AD}=$ adduction, $\mathrm{AFO}=$ ankle-foot orthosis, $\mathrm{DF}=$ dorsiflexion, $\mathrm{EAFO}=$ experimental $\mathrm{AFO}, \mathrm{EV}=$ eversion, $\mathrm{EXT}=$ external rotation, $\mathrm{FX}=$ flexion, $\mathrm{IN}$ = inversion, $\mathrm{INT}=$ internal rotation, $\mathrm{MTP}=$ metartarsophalangeal, $\mathrm{NA}=$ not available, $\mathrm{PF}=$ plantar flexion, $\mathrm{ROM}=$ range of motion.

moments in three planes and plotted a moment-angle hysteresis curve following application of a force in a single plane [17] or measured the distance of a deflection in the sagittal plane to evaluate and compare AFO rigidity $[12,18]$. Analog dial gauges can measure the deflection of an AFO statically at a certain position, but they cannot measure it continuously over the range of motion. Compared with tensionmeters, dial gauges showed an advantage in that they enabled quantification of AFO rigidity in multiple planes. However, the designs in the literature that incorporated dial gauges did not appear feasible in the clinical setting because of their complexity. Deflection force was applied via a surrogate limb in two studies [12,17], while it was directly applied at the posterior wall of the AFO in another study [18]. Direct attachment of a dial gauge to the AFO would be influenced by the geometry, thickness, 
and deformation of the location of the gauge's attachment to the AFO.

\section{Studies Using Strain Gauges or Load Cells}

Strain gauges can measure strain, while load cells are made of strain gauges and can measure the loading force. Measuring AFO rigidity with use of an apparatus constructed with strain gauges or load cells may enable more accurate measurement of rigidity because strain gauges and load cells are generally more sensitive than tensionmeters or dial gauges. An apparatus built with strain gauges or load cells allows continuous measurement of rigidity at a particular speed in the specific range of motion. However, a biomechanical model would be required to analyze the data [19,21-24]. Although the modeling itself is not essentially unfavorable, constructing a model for each different type of AFO would be time-consuming and make the test complicated [5]. Moreover, accurate measurement and alignment of an AFO on the device would require great effort [5]. Strain gauges have been used to quantify the relationship between the kinetic and kinematic data acquired from AFO deformation by using analysis of the foot section motion relative to the shank and have demonstrated a direct correlation between the two parameters [19]; they have also been used to quantify the moment-angle relationship of an AFO together with a potentiometer [20]. Utilizing load cells, a fully automatic loading apparatus has been developed to apply controlled joint angular displacement at the ankle portion of the AFO and measure corresponding moments in three anatomical planes [23]. Alternatively, a manual device that based its design on a surrogate human leg model and could measure both ankle and metatarsophalangeal (MTP) joint stiffness has been developed [21]. This device was the first designed to measure stiffness of the MTP joint region of an AFO and to simulate the stiffness effect of an AFO/footwear combination. The device was subsequently used to demonstrate the feasibility of matching AFO stiffness to the individual patient's needs [2]. The automated device would be appealing in industry, while the manual device would have more potential for clinical use because of its portability and convenience.

\section{Studies Using Muscle Training Machines}

A muscle training machine is commonly used for rehabilitation in the clinical setting. An apparatus based on the muscle training machine has been developed [25]. This was the only bench analysis found in the literature in which a human limb was used instead of a surrogate limb. The viscoelastic properties of a human limb would affect the rigidity of an AFO, and the result would have been different if a surrogate limb had been used. A similar device was used to examine mechanical properties of an AFO with an oil-damper joint without a surrogate limb [26]. Use of a muscle training machine would be an attractive alternative to custom-made automated apparatuses in the clinical setting.

\section{Studies Using Forceplates}

Forceplates are commonly installed in gait laboratories to evaluate the kinetics of gait performance. Novacheck et al. quantified stiffness of AFOs with a device that interfaces with a forceplate by designing a jig that fixes the AFO firmly to the forceplate with reflective markers attached to a surrogate limb and the foot segment of the AFO and then applying a manual force [11]. This device enabled the plotting of moment-angle curves. It appeared that an experimental apparatus using a forceplate would be able to obtain full three-dimensional measurements. Because the AFO stiffness data acquired from the combined use of forceplate and infrared camera technology are highly accurate, use of this technology is attractive for clinical or research environments where three-dimensional gait analysis is conducted regularly and is worthy of further investigation. However, use of this technology may not be feasible in the regular clinical setting because of the equipment's expense and space requirements.

\section{Studies Using Mechanical Testing Machines}

Mechanical testing machines are commonly used in industry to examine and characterize the fatigue resistance of an orthopedic product. Use of a mechanical testing machine would be particularly effective for cyclic testing, and its influence on AFO rigidity has been investigated [27,29-30]. Mechanical testing machines have also enabled accurate repetitive measurement of AFO stiffness in combination with a torquemeter [5]. Use of a mechanical device therefore enables an apparatus to be built that can perform repeatedly under well-controlled torques, velocities, or ranges of motion. Therefore, a mechanical testing machine is preferred for use in industry but may not be ideal in the clinical setting because of its complexity, size, and cost.

\section{Functional Analysis}

Functional analysis has involved the use of strain gauges [6,31-34] or experimental AFOs [7-8,35-37] to quantify the effect of an AFO intervention. 


\section{Studies Using Strain Gauges}

When attached at the area of interest, strain gauges can measure the stresses or loads acting on an AFO. The first series of functional analyses of AFOs used strain gauges to measure stresses or loads on the uprights of metal AFOs [31-34]. Tensile and compressive stresses around the ankle region of thermoplastic AFOs were subsequently quantified [6]. Using strain gauges to evaluate and identify the location where mechanical failure may occur through examination of the location of peak stress within the newly designed AFO appears reasonable in industry; however, their clinical use seems limited.

\section{Studies Using Experimental Ankle-Foot Orthoses}

A series of functional studies have been conducted with experimental AFOs whose ankle joint resistance to plantar flexion and dorsiflexion directions could be adjusted in an attempt to quantify an optimal AFO rigidity for patients with a gait-limiting pathology [7-8,35-36]. These studies developed techniques to quantify the moment generated by an AFO separately from the moment generated by the floor reaction force and muscles during gait. The results of these studies indicated that the dorsiflexion assistive moment at initial contact was comparatively larger than that during swing phase to prevent drop-foot in patients with hemiplegia; recommendations for AFO design were therefore proposed [37]. The desirable AFO for patients with hemiplegia was recommended to have an articulated orthotic ankle joint to provide a fair amount of inversion and eversion corrective moment, an initial dorsiflexion angle between $0^{\circ}$ and $10^{\circ}$, an adjustable range of motion between $30^{\circ}$ of dorsiflexion and $10^{\circ}$ of plantar flexion, no plantar flexion assistive moment, and dorsiflexion assistive moment during ankle plantar flexion (5-20 N.m/10 of plantar flexion) [37]. A dorsiflexion assist controlled by spring (DACS) AFO [20] and an AFO with an oil-damper joint [26] were subsequently developed based on these studies and tested for efficacy. These criteria have indicated the ankle joint moments to be expected when a patient is walking with an AFO and should inform the development of appropriate mechanisms to mechanically test AFOs with appropriate loading rates. An experimental AFO would be a useful asset in the clinical setting once redesigned to be more user-friendly and cosmetic than current designs and once a method could be established to transfer the information from the experimental AFO to a definitive AFO. In industry, evaluating the specific requirement of a newly designed AFO in a target group of patients would also be useful.

\section{Fixation of Ankle-Foot Orthoses for Bench Analysis}

Those studies that used a surrogate limb encapsulated by the AFO during bench testing applied the deformation force indirectly via a longitudinal bar positioned through the center of the shank [2,4,9-11,16,21,23] or an angled wedge connected to its proximal end in an attempt to simulate both static and dynamic loading of an AFO during nondisabled gait [12] (Table). Using a surrogate limb has its merits because, feasibly, it could more accurately reflect loading during functional ambulation, especially if the AFO being tested were molded to accurately fit the surrogate limb profile and, if mechanically controlled, could provide acceptable repeatability. Some authors have reported possible weaknesses in their testing method by not including a mechanical ankle joint in their surrogate leg model $[5,24]$.

Most articles that used a tensionmeter or other mechanical means to apply a bending moment to the AFO also used bolts or clamps to fix the footplate of the AFO to a measurement apparatus or a baseplate. However, in those cases where the AFO was not strapped to a surrogate lower-limb model but left free to deflect between the application point and the clamped or bolted footplate, unwanted axial torsional effects could have occurred during deflection testing. In addition, fixation of the footplate of the AFO to the device would result in testing of only the ankle and calf region [12]. One study, however, not only secured the base of the AFO to a flat surface but also provided a pivot point equivalent to the metatarsal head level to simulate the effect of footplate deflection at the MTP joint [21]. Another study left the footplate free to interface with a level surface while being loaded proximally to more accurately simulate ambulatory effects of $\mathrm{AFO} /$ footwear combinations using a surrogate limb via a wedge applicator at the proximal aspect to simulate walking [12]. The superstructure was not clamped at the footplate, which allowed use of footwear on a low-friction contact plate [12].

\section{Angular Range Used in Testing}

The range of motion of the ankle joint has been shown to fall within $10^{\circ}$ of dorsiflexion to $5^{\circ}$ of plantar flexion in patients with stroke hemiplegia wearing an articulated AFO [39]. Evidence in the literature has demonstrated a large variety in the ranges of motion in the sagittal plane used during testing protocols, which ranged from $20^{\circ}$ of plantar flexion to $30^{\circ}$ of dorsiflexion (Table). An articulated AFO was tested over the range of $15^{\circ}$ of 
plantar flexion to $15^{\circ}$ of dorsiflexion, because this sufficiently covered the range of its typical orthotic ankle joint movement during ambulation in patients with hemiplegia [5]. In general, the range used in testing should cover the physiological range of motion of the ankle joint of a target group of patients for a tested AFO.

\section{Angular Velocity Used in Testing}

The reported range of angular velocities used in the test is $0.5 \%$ s to $50 \%$ [4-5,16,24-26,30] (Table). However, angular velocity reportedly does not affect the stiffness of a thermoplastic AFO [11,25]. One study using a muscle testing apparatus reported no effect on the stiffness (moment vs deflection angle) of various thermoplastic AFOs when tested at different velocities between $5 \%$ and $50 \%$ [25], while another study that used a forceplate to test AFOs also reported no effect of the applied velocity on their stiffness [11]. However, an AFO with oildamper joint revealed a velocity-dependent effect in its stiffness [26]. Therefore, testing at different levels of velocity would be required to evaluate an AFO constructed of a material with velocity-dependent properties.

\section{Accuracy and Repeatability}

Hand-held tensionmeters alone [15], using a protractor via a winch [9], or in parallel with a protractor $[4,16]$ or goniometer $[10,13]$ may have inherent errors, which can be quantified but may also affect repeatability, especially if in series, giving a cumulative effect. The reliability of the majority of testing devices found in the literature remains questionable [21]. However, some articles published during the last 10 years have demonstrated numerical accuracy or repeatability in the testing methods used [5,21,23-24]. This has been assessed by uncertainty [23], standard deviations [5], generalizability study (G-study) [21] or coefficient of repeatability [24]. The G-study determines the influence of multiple sources of error variance in measurements by using error of measurement or the smallest detectable difference [21], while the coefficient of repeatability quantifies the measurement repeatability of the testing method [24].

\section{DISCUSSION AND RECOMMENDATIONS}

This article reviewed studies on the analysis of AFO rigidity properties via bench testing and functional conditions. The advantages of functional analysis studies are that they can analyze the rigidity properties of a dynamic system consisting of an $\mathrm{AFO} /$ footwear combination and determine how the system affects lower-limb joint kinematics and kinetics [5]. However, a number of factors that would derive from patients' characteristics, such as the nature of pathology or the level of gait disability, might influence the results obtained; therefore, comparisons between subjects with different conditions would be difficult to interpret [5]. Moreover, transferring the stiffness characteristics logged from an experimental AFO to a definitive AFO would be necessary because its design is currently uncosmetic [7-8].

Conversely, bench-testing analysis would enable more accurate control of the experimental conditions and theoretically improve repeatability [5]. The issue with bench testing is how accurately it reflects the loading experienced by an AFO when different patient groups wear it during ambulation [5]. Recent articles have suggested that the required accuracy might be achieved $[12,21]$ — but a cost-effective clinical device is needed to evaluate patients as well. Moreover, most of the testing methods developed to quantify the rigidity characteristics of AFOs are complex and therefore would be difficult to apply clinically. The feasibility of conducting AFO rigidity testing with the use of portable equipment should therefore be further explored.

AFO stiffness is defined as the moment around the ankle joint exerted by the AFO per degree of ankle joint rotation and should be computed as a slope of the momentangle curve (newton-meters/degree) [5]. Some studies used stiffness as a parameter of AFO rigidity [5,21,23], while other studies instead chose to state the maximum bending moment resisted or applied by the AFO tested and the angle at which this occurred in plantar flexion and/or dorsiflexion $[4,10,16]$. Stiffness of AFOs has been mostly measured in the sagittal plane; however, measurement in the coronal plane [17,22-25] or transverse plane [17] has also been reported. Yamamoto et al. (1997) reported that for patients with stroke hemiplegia, an optimal articulated AFO should allow adjustment of plantar flexion resistive stiffness in the range of $0.5 \mathrm{~N} \cdot \mathrm{m} /{ }^{\circ}$ to $2.0 \mathrm{~N} \cdot \mathrm{m} /{ }^{\circ}$ [37] and subsequently developed a DACS AFO $\left(0.20 \mathrm{~N} \cdot \mathrm{m} /{ }^{\circ}\right.$ to $\left.1.70 \mathrm{~N} \cdot \mathrm{m} /{ }^{\circ}\right)$ [20] and an AFO with an oil-damper joint $\left(0.50 \mathrm{~N} \cdot \mathrm{m} /{ }^{\circ}\right.$ to $1.40 \mathrm{~N} \cdot \mathrm{m} /{ }^{\circ}$ ) [26]. Bregman et al. (2009) reported that the stiffness of nonarticulated AFOs ranged from $0.20 \mathrm{~N} \cdot \mathrm{m} /{ }^{\circ}$ to $1.56 \mathrm{~N} \cdot \mathrm{m} /{ }^{\circ}$, depending on the material and design [21]. This result suggests that an appropriately designed nonarticulated AFO could achieve the plantar flexion resistive stiffness range suggested by Yamamoto et al. [37]. The 
advantage of using stiffness as a parameter of measurement is that it enables the AFO rigidity to be easily compared with gait or other biomechanical analysis data, such as joint moment or stiffness [38]. Therefore, using stiffness as a measurement parameter will be especially effective for matching AFO stiffness to individual need based on these data.

AFO design factors, such as geometric configuration and material selection, plus experimental factors, such as consistency in the experimental procedures among different trials, accuracy of the sensors, and methodologies used, could introduce errors in the results obtained. Various types of surrogate legs were also used to simulate a human limb in bench-testing analyses. However, the reliability of the measurement methods and apparatuses were generally lacking [21]. A reliability test of the measurement should therefore be included in future studies.

The type of mechanical ankle joint used in an AFO should be as congruent as possible to the center of rotation of a human ankle joint, and the material of a surrogate leg should be as similar as possible to that of a human limb. However, the surrogate limbs used in the past studies were simple ones that rotated in the sagittal plane $[4,9,11-13,16-17,19,21,23-24]$. Only one study was conducted in which a human limb was used to measure the stiffness of an AFO in a bench-testing condition [25]. This was significant because the viscoelastic properties of a human limb will undoubtedly affect the mechanical performance of an AFO. Therefore, even a bench analysis of AFOs should replicate these effects.

In one study, an apparatus to simulate the physiological forces acting on an AFO during ambulation was developed [12]. This study was in contrast to most other studies in which AFOs were simply clamped and deflected. The method of conducting bench analyses should therefore mimic forces experienced during a gait cycle as closely as possible. Thus, considering the effect of an AFO on gait, the following factors at different phases of the gait cycle should be considered and quantified when the bench analysis is conducted:

1. The presence of appropriate AFO ankle-region stiffness to allow smooth plantar flexion at initial contact (heel rocker).

2. Adequate AFO ankle-region stiffness to allow good control of dorsiflexion at midstance (ankle rocker).

3. Ankle- and MTP-region stiffness to enable smooth transition from terminal stance to swing phase (forefoot rocker).
4. Ankle-region stiffness for enough clearance in the swing phase.

An ankle-foot stimulator constructed with a surrogate limb, a forceplate, a servo motor, and infrared cameras was developed to investigate AFO fatigue failure [40]. It attempted to simulate a gait cycle during bench testing and, therefore, appeared to be able to incorporate the above factors. [40]. Therefore, a further study on the feasibility of using this apparatus to investigate AFO stiffness is appealing.

The method of fixation and alignment of an AFO as well as the application of forces will affect the deflection measurements during bench analysis. Bregman et al. reported that previous studies have neglected to measure the neutral angle of an AFO [21]. Therefore, a recent article demonstrated the use of a plumb line to determine the neutral angle of an articulated AFO [5]. Some studies require the drilling of holes to fix the AFOs to the apparatus, which is undesirable in the clinical setting [17-18]. Thus, the apparatus should be designed to fix the AFOs in a nondestructive manner.

Two patterns of force application techniques were used in precedence bench-testing analyses [5]: (1) exerting force to a certain region of an AFO $[10,15,18]$ or (2) exerting force via a surrogate limb [4-5,9,11-13,1617,19,21,23-24]. Application of force via a surrogate limb could simulate the loading pattern of a lower limb, as discussed earlier. Footwear would also influence the mechanical behavior and alignment of an AFO; however, its influence on AFO gait biomechanics has only recently been studied [41]. Development of a proper surrogate leg, whose joint is properly aligned to a physiological ankle joint and surface finishing closely replicates the viscoelastic properties of skin and its underlying tissues, is required so that it truly reflects the dynamic mechanics experienced by AFOs combined with shoes for benchtesting analyses [5]. Once a reliable method is established, exploring how to interpret a measurement result to match the need of an individual patient in the clinical setting will be necessary [2-4]. In the industry setting, establishing a pathway to apply the bench-testing technique for quality control of an AFO will be required.

Functional analyses need to establish repeatable experimental methods with high reliability that minimize alteration to external parameters from human ambulation and internal parameters from type of disease and disability of a patient. Once a reliable method is established, 
exploring a way to transfer stiffness from an experimental AFO to a definitive AFO will be necessary.

Therefore, the following aspects of AFO stiffness analysis will require further investigations:

- Optimal fixation and alignment of an AFO to the apparatus.

- Development of a better surrogate limb system with a properly aligned joint and surface finishing that replicates human skin.

- Influence of AFO/footwear combinations on stiffness and gait biomechanics.

- Control of parameters that influence functional analyses.

- Transfer of stiffness from an experimental AFO to a definitive AFO.

- Establishment of the accuracy and reliability of a measurement method.

- Clinical application of the measurement result to assist a prescription.

- Matching of stiffness of an AFO to each patient.

- Pathways toward quality control of an AFO in the industrial setting.

The following recommendations for development of appropriate AFO stiffness measurement protocols have therefore evolved from this literature review:

- Evidence to match AFO stiffness to individual patient requirements in the clinical setting should be considered and further explored [2-3].

- The simulation of MTP joint motion or use of AFO/ footwear combinations should be used in the testing method to more accurately reflect human gait $[12,21]$.

- Measurement of the AFO neutral angle should be included when AFO stiffness at the ankle and metatarsal head regions are analyzed [5,21].

- Moments and angles should be defined to compute stiffness as routinely documented in gait laboratory reports [17,25].

- A portable and low-cost device that demonstrates acceptable repeatability and reliability for clinical use should be developed [16,21].

- The angular velocity and range of motion used in bench testing should reflect those of the ankle joint documented for nondisabled or pathological gait $[5,26]$.

- The method used to deflect the AFO should mimic human walking and be modeled accordingly $[12,40]$.

- Accuracy and repeatability analyses should be included in the testing [21,24].
- AFO stiffness should be defined by the computation of the slope of the moment-angle curve (newton-meters/ degree) acquired following testing $[11,23]$.

\section{CONCLUSIONS}

The feasibility of matching AFO stiffness to the patient's requirement for optimal gait based on gait analysis data must be explored. However, recent studies have suggested the possibility of collecting such data through combined functional and bench testing: the motions measured during pathological walking by gait analysis can be applied to a bench-testing apparatus.

We conducted a literature review of AFO rigidity analysis. AFO rigidity analysis may be grouped into bench and functional techniques. Understanding the strengths and weaknesses of each method is crucial to establishing an analysis method practical for clinical use in the development of a patient-centered AFO prescription system and for AFO quality assurance in industry.

\section{ACKNOWLEDGMENTS}

\section{Author Contributions:}

Study concept and design: T. Kobayashi.

Acquisition of data: T. Kobayashi, S. W. Hutchins.

Analysis and interpretation of data: T. Kobayashi, S. W. Hutchins,

A. K. L. Leung.

Drafting of manuscript: T. Kobayashi, S. W. Hutchins.

Critical revision of manuscript for important intellectual content:

T. Kobayashi, S. W. Hutchins, A. K. L. Leung.

Obtained funding: T. Kobayashi, A. K. L. Leung.

Study supervision: A. K. L. Leung.

Financial Disclosures: The authors have declared that no competing interests exist.

Funding/Support: This material was based on work funded by The Hong Kong Polytechnic University International Postgraduate Scholarships for PhD Studies.

\section{REFERENCES}

1. Condie DN, Meadows CB. Ankle-foot orthoses. In: Bowker P, Brader DL, Pratt DJ, Condie DN, Wallace AW, editors. Biomechanical basis of orthotic management. Oxford (England): Butterworth-Heinemann; 1993. p. 99-123.

2. Bregman DJ, De Groot V, Van Diggele P, Meulman H, Houdijk H, Harlaar J. Polypropylene ankle foot orthoses to overcome drop-foot gait in central neurological patients: A 
mechanical and functional evaluation. Prosthet Orthot Int. 2010;34(3):293-304. [PMID: 20738233]

DOI:10.3109/03093646.2010.495969

3. Harlaar J, Brehm M, Becher JG, Bregman DJ, Buurke J, Holtkamp F, De Groot V, Nollet F. Studies examining the efficacy of ankle foot orthoses should report activity level and mechanical evidence. Prosthet Orthot Int. 2010;34(3): 327-35. [PMID: 20738235] DOI:10.3109/03093646.2010.504977

4. Sumiya T, Suzuki Y, Kasahara T. Stiffness control in posteriortype plastic ankle-foot orthoses: Effect of ankle trimline. Part 2: Orthosis characteristics and orthosis/patient matching. Prosthet Orthot Int. 1996;20(2):132-37. [PMID: 8876008]

5. Kobayashi T, Leung AK, Akazawa Y, Naito H, Tanaka M, Hutchins SW. Design of an automated device to measure sagittal plane stiffness of an articulated ankle-foot orthosis. Prosthet Orthot Int. 2010;34(4):439-48. [PMID: 20681928] DOI:10.3109/03093646.2010.495370

6. Chu TM, Feng R. Determination of stress distribution in various ankle-foot orthoses: Experimental stress analysis. J Prosthet Orthot. 1998;10(1):11-16. DOI:10.1097/00008526-199801010-00004

7. Yamamoto S, Ebina M, Kubo S, Kawai H, Hayashi T, Iwasaki M, Kubota T, Miyazaki S. Quantification of the effect of dorsi-/plantarflexibility of ankle-foot orthoses on hemiplegic gait: A preliminary report. J Prosthet Orthot. 1993;5(3):88-94.

8. Yamamoto S, Miyazaki S, Kubota T. Quantification of the effect of the mechanical property of ankle-foot orthoses on hemiplegic gait. Gait Posture. 1993;1(1):27-34.

DOI:10.1016/0966-6362(93)90040-8

9. Golay W, Lunsford T, Lunsford BR, Greenfield J. The effect of malleolar prominence on polypropylene AFO rigidity and buckling. J Prosthet Orthot. 1989;1(4):231-42. DOI:10.1097/00008526-198907000-00007

10. Nagaya M. Shoehorn-type ankle-foot orthoses: Prediction of flexibility. Arch Phys Med Rehabil. 1997;78(1):82-84. [PMID: 9014963] DOI:10.1016/S0003-9993(97)90015-0

11. Novacheck TF, Beattie CB, Rozumalski A, Gent G, Kroll G. Quantifying the spring-like properties of ankle-foot orthoses (AFOs). J Prosthet Orthot. 2007;19(4):98-103. DOI:10.1097/JPO.0b013e31812e555e

12. Polliack AA, Swanson C, Landsberger SE, McNeal DR. Development of a testing apparatus for structural stiffness evaluation of ankle-foot orthoses. J Prosthet Orthot. 2001; 13(3):74-82. DOI:10.1097/00008526-200109000-00012

13. DeToro WW. Plantarflexion resistance of selected ankle-foot orthoses: A pilot study of commonly prescribed prefabricated and custom-molded alternatives. J Prosthet Orthot. 2001; 13(2):39-44. DOI:10.1097/00008526-200106000-00012
14. Ohsawa S, Ikeda S, Tanaka S, Takahashi T, Takeuchi T, Utsunomiya M, Ueno R, Ohkura M, Ito Y, Katagi Y, Ueta M, Hirano T. A new model of plastic ankle foot orthosis (FAFO (II)) against spastic foot and genu recurvatum. Prosthet Orthot Int. 1992;16(2):104-8. [PMID: 1408667]

15. Rubin G, Dixon M. Modern ankle-foot orthoses (AFO’s). Bull Prosthet Res. 1973;10(19):20-41. [PMID: 4358417]

16. Sumiya T, Suzuki Y, Kasahara T. Stiffness control in posterior-type plastic ankle-foot orthoses: Effect of ankle trimline. Part 1: A device for measuring ankle moment. Prosthet Orthot Int. 1996;20(2):129-31. [PMID: 8876007]

17. Klasson B, Convery P, Raschke S. Test apparatus for the measurement of the flexibility of ankle-foot orthoses in planes other than the loaded plane. Prosthet Orthot Int. 1998;22(1):45-53. [PMID: 9604275]

18. Ross RS, Greig RJ, Convery P. Comparison of bending stiffness of six different colours of copolymer polypropylene. Prosthet Orthot Int. 1999;23(1):63-71. [PMID: 10355646]

19. Singerman R, Hoy DJ, Mansour JM. Design changes in ankle-foot orthoses intended to alter stiffness also alter orthosis kinematics. J Prosthet Orthot. 1999;11(3):48-55. DOI:10.1097/00008526-199901130-00002

20. Yamamoto S, Ebina M, Kubo S, Hayashi T, Akita Y, Hayakawa Y. Development of a new ankle-foot orthosis with dorsiflexion assist, part 2: Structure and evaluation. J Prosthet Orthot. 1999;11(2):24-28.

21. Bregman DJ, Rozumalski A, Koops D, De Groot V, Schwartz M, Harlaar J. A new method for evaluating ankle foot orthosis characteristics: BRUCE. Gait Posture. 2009; 30(2):144-49. [PMID: 19520576] DOI:10.1016/j.gaitpost.2009.05.012

22. Cappa P, Patanè F, Pierro MM. A novel device to evaluate the stiffness of ankle-foot orthosis devices. J Biomech Eng. 2003;125(6):913-17. [PMID: 14986419] DOI:10.1115/1.1634993

23. Cappa P, Patanè F, Di Rosa G. A continuous loading apparatus for measuring three-dimensional stiffness of anklefoot orthoses. J Biomech Eng. 2005;127(6):1025-29.

[PMID: 1643244]

DOI:10.1115/1.2049313

24. Ringleb SI, Armstrong T, Berglund LJ, Kitaoka HB, Kaufman KR. Stiffness of the Arizona ankle-foot orthosis before and after modification for gait analysis. J Prosthet Orthot. 2009;21(4):204-7. DOI:10.1097/JPO.0b013e3181bfb28e

25. Yamamoto S, Ebina M, Iwasaki M, Kubo S, Kawai H, Hayashi T. Comparative study of mechanical characteristics of plastic AFOs. J Prosthet Orthot. 1993;5(2):59-64.

26. Yamamoto S, Hagiwara A, Mizobe T, Yokoyama O, Yasui T. Development of an ankle-foot orthosis with an oil damper. Prosthet Orthot Int. 2005;29(3):209-19. [PMID: 16466151] DOI:10.1080/03093640500199455 
27. Braund M, Kroontje D, Brooks J, Self B, Aaron G, Bearden $\mathrm{K}$. Analysis of stiffness reduction in varying curvature ankle foot orthoses. Biomed Sci Instrum. 2005;41:19-24. [PMID: 15850076]

28. Condie DN, Meadows CB. Some biomechanical considerations in the design of ankle-foot orthoses. Orthot Prosthet. 1977;31(3):45-52.

29. Lunsford TR, Ramm T, Miller JA. Viscoelastic properties of plastic AFOs. J Prosthet Orthot. 1994;6(1):3-9. DOI:10.1097/00008526-199400610-00002

30. Major RE, Hewart PJ, MacDonald AM. A new structural concept in moulded fixed ankle foot orthoses and comparison of the bending stiffness of four constructions. Prosthet Orthot Int. 2004;28(1):44-48. [PMID: 15171577]

31. Magora A, Robin GC, Adler E, Libai A, Eitan A. Dynamic strain analysis of below-knee orthopedic braces. A preliminary report. Am J Phys Med. 1968;47(1):31-40.

[PMID: 5644317]

32. Robin GC, Magora A, Adler E, Saltiel J. Dynamic stress analysis of below-knee drop foot braces. Med Biol Eng. 1968;6(5):533-46. [PMID: 5713523] DOI:10.1007/BF02474292

33. Robin GC, Magora A. Dynamic stress analysis of belowknee drop foot braces; studies on patients with paralysis of the lower limb. Med Biol Eng. 1969;7(2):221-26.

[PMID: 5802207]

DOI:10.1007/BF02474178

34. Robin GC, Magora A, Saltiel J, Adler E. Dynamic analysis of plastic below-knee drop foot braces. Med Biol Eng. 1971;9(6):631-36. [PMID: 5158815]

DOI:10.1007/BF02474643

35. Miyazaki S, Yamamoto S, Ebina M, Iwasaki M. A system for the continuous measurement of ankle joint moment in hemiplegic patients wearing ankle-foot orthoses. Front Med Biol Eng. 1993;5(3):215-32. [PMID: 8280669]

36. Miyazaki S, Yamamoto S, Kubota T. Effect of ankle-foot orthosis on active ankle moment in patients with hemiparesis. Med Biol Eng Comput. 1997;35(4):381-85.

[PMID: 9327616]

DOI:10.1007/BF02534094
37. Yamamoto S, Ebina M, Miyazaki S, Kawai H, Kubota T. Development of a new ankle-foot orthosis with dorsiflexion assist, part 1: Desirable characteristics of ankle-foot orthoses for hemiplegic patients. J Prosthet Orthot. 1997;9(4):74-79. DOI:10.1097/00008526-199700940-00009

38. Kobayashi T, Leung AK, Akazawa Y, Tanaka M, Hutchins SW. Quantitative measurement of spastic ankle joint stiffness using a manual device: A preliminary study. J Biomech. 2010;43(9):1831-34. [PMID: 20189176] DOI:10.1016/j.jbiomech.2010.02.024

39. Fatone S, Gard SA, Malas BS. Effect of ankle-foot orthosis alignment and foot-plate length on the gait of adults with poststroke hemiplegia. Arch Phys Med Rehabil. 2009; 90(5):810-18. [PMID: 19406301] DOI:10.1016/j.apmr.2008.11.012

40. Lai HJ, Yu CH, Kao HC, Chen WC, Chou CW, Cheng CK. Ankle-foot simulator development for testing ankle-foot orthoses. Med Eng Phys. 2010;32(6):623-29.

[PMID: 20439163]

DOI:10.1016/j.medengphy.2010.03.008

41. Owen E. The importance of being earnest about shank and thigh kinematics especially when using ankle-foot orthoses. Prosthet Orthot Int. 2010;34(3):254-69. [PMID: 20738230] DOI:10.3109/03093646.2010.485597

Submitted for publication October 5, 2010. Accepted in revised form December 14, 2010.

This article and any supplementary material should be cited as follows:

Kobayashi T, Leung AKL, Hutchins SW. Techniques to measure rigidity of ankle-foot orthosis: A review. J Rehabil Res Dev. 2011;48(5):565-76.

DOI:10.1682/JRRD.2010.10.0193

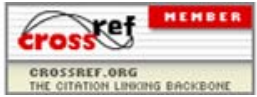

